\title{
PANORAMA DOS PROGRAMAS DE BIOCOMBUSTÍVEIS AMERICANO, BRASILEIRO E EUROPEU
}

\author{
Sérgio Rangel Fernandes Figueira ${ }^{1}$
}

\begin{abstract}
RESUMO
Os governos do Brasil, Estados Unidos e o parlamento da União Europeia elaboraram programas para intensificar a utilização de biocombustíveis com a principal justificativa de reduzir a utilização de combustíveis fósseis e consequentemente da emissão de gases do efeito estufa. O objetivo do artigo foi o de realizar uma pesquisa bibliográfica e documental para se descrever os principais aspectos das políticas públicas para se incentivar o consumo e a produção de biocombustíveis e a variação efetiva da oferta e da demanda de biocombustíveis nestas regiões. Constatou-se efetivo crescimento da oferta e da demanda de biocombustíveis em todos os programas analisados no final da década de 2000. No entanto, no início da década de 2010 os programas de biocombustíves entram em estagnação. Os Estados Unidos tornaram-se os maiores produtores de biocombustíveis no mundo, superando 40 bilhões de litros no ano de 2010. A produção brasileira de etanol destinada basicamente ao mercado interno atingiu aproximadamente 25 bilhões de litros de etanol na safra 2008/09 e 3,4 bilhões de litros de biodiesel em 2014. Na União Europeia, a produção e consumo estabilizou-se em aproximadamente 20 bilhões de litros. Ressalta-se ainda para o fato de o etanol ser o principal biocombustível no Brasil e Estados Unidos e o Biodiesel na União Europeia, com aproximadamente $75 \%$ do consumo de biocombustíveis. No Brasil, iniciou-se um programa de mistura de biodiesel no óleo disel a partir de 2008.
\end{abstract}

PALAVRAS-CHAVE: Programas de biocombustíveis nos Estados Unidos. Brasil. União Europeia.

\section{BIOFUELS PROGRAMS AMERICAN, EUROPEAN AND BRAZILIAN}

\begin{abstract}
The governments of Brazil, the United States and the parliament of the European Union have developed programs to increase the use of biofuels with the main justification to reduce the use of fossil fuels and therefore the emission of greenhouse gases. The goal of the article was to perform a bibliographic and documentary research to describe the the main aspects of public policies to encourage the consumption and production of biofuels and the effective change in supply and demand for biofuels in these regions. It was found effective growth of supply and demand of biofuels in all
\end{abstract}

\footnotetext{
${ }^{1}$ Professor Doutor na Faculdade de Ciências Agrárias e Veterinárias da UNESP de Jaboticabal. figueira@fcav.unesp.br
} 
programs analyzed in the late 2000s, however, in the early 2010s the biofuel programs come into stagnation. The United States has become the largest biofuel producers in the world, surpassing 40 billion liters in 2010. The growth of Brazilian ethanol production destined mainly to the domestic market reached about 25 billion liters of ethanol in the harvest 2008/09 and 3.4 billion liters of biodiesel in 2014. In the European Union, the production and consumption stabilized at about 20 billion liters. It is also noteworthy for the fact that ethanol is the main biofuel in Brazil and in the United States and the Biodiesel in European Union, with approximately $75 \%$ of the consumption of biofuels. In Brazil, it began a biodiesel blend program in disel oil from 2008.

KEY-WORDS: Biofuels programs in the United States. Brazil. European Union

\title{
BIOCOMBUSTIBLES PROGRAMAS AMERICANOS, EUROPEOS Y BRASILEÑOS.
}

\begin{abstract}
RESUMEN
Los gobiernos de Brasil, Estados Unidos y el Parlamento de la Unión Europea han desarrollado programas para aumentar el uso de biocombustibles con la justificación principal para reducir el uso de combustibles fósiles $y$, por tanto, la emisión de gases de efecto invernadero. El propósito del artículo es realizar una investigación bibliográfica y documental para descripción de los aspectos principales de las políticas públicas para fomentar el consumo y la producción de biocombustibles y el cambio efectivo en la oferta y la demanda de los biocombustibles en estas regiones. Se encontró crecimiento efectivo de la oferta y la demanda de los biocombustibles en todos los programas analizados en la década de 2000, sin embargo, a principios de los 2010s, los programas biocombustíves entran en el estancamiento. Los Estados Unidos se ha convertido en los mayores productores de biocombustibles en el mundo, superando los 40 mil millones de litros en 2010. La producción brasileña de etanol para el mercado interno, básicamente, llegó a unos 25 millones de litros de etanol en 2008/09 y 3,4 mil millones de litros de biodiesel en 2014. En la Unión Europea, la producción y el consumo se estabilizó en alrededor de 20 mil millones de litros. También es digno de mención el hecho de que el etanol es el biocombustible principal en Brasil y Estados Unidos y el biodiesel en la UE, con alrededor del $75 \%$ del consumo de biocombustibles. En Brasil, se inició un programa de mezcla de biodiesel en el aceite de diesel de 2008.
\end{abstract}

PALABRAS-CLAVE: Programas de biocombustibles en Estados Unidos. Brasil. Unión Europea

\section{INTRODUÇÃO}

A concentração de determinados gases, principalmente o dióxido de carbono $\left(\mathrm{CO}_{2}\right)$, na atmosfera da Terra causam o efeito estufa. O efeito estufa natural permitiu a manutenção da existência de vida no planeta ao manter as temperaturas na Terra. Sem o efeito estufa natural a terra seria um mero deserto gelado (PEREIRA; MAY, 2003). 
O agravamento do efeito estufa tem sido gerado pelas atividades humanas como o uso de combustíveis fósseis, principalmente derivados do petróleo, para a geração de energia, o desflorestamento e a atividade agropecuárias. A intensificação das atividades produtivas para abastecer a uma crescente população mundial ampliam a emissão de gases geradores do efeito estufa e consequentemente ampliando a temperatura do planeta (BRASIL, 1999).

Devido a preocupação com as mudanças climáticas, em junho de 1988, realizou-se a Conferência Mundial sobre Mudanças Atmosférica. Após a conferência, estabeleceu-se o Painel Intergovernamental sobre Mudança Climática, um grupo de trabalho encarregado de respaldar técnica e cientificamente as negociações desse tratado internacional. Em 1990, publicou-se um Primeiro Relatório de Avaliação, afirmando que a mudança climática representaria de fato uma ameaça à humanidade alertando sobre algumas das possíveis conseqüências: elevação do nível dos oceanos; mudanças nos regimes de chuvas e ventos, com intensificação de fenômenos tais como furacões, tufões, ciclones, tempestades tropicais e inundações; perda de áreas agrícolas; intensificação do processo de desertificação e de acesso à água potável, etc. (PEREIRA; MAY, 2003).

$\mathrm{Na}$ terceira Conferência entre as partes (COP-3) realizada em Quioto, no Japão, em 1997, institui-se o Protocolo de Quioto incluindo metas e prazos relativos à redução ou limitação das emissões futuras de gases do efeito estufa. O Protocolo dividiu os países em dois grupos: o Anexo 1 (países mais industrializados, grandes emissores de $\mathrm{CO}_{2}$ ) e os países do Não-anexo 1 (países que podem aumentar suas emissões, pois necessitam aumentar a sua oferta energética, para atender às necessidades básicas de desenvolvimento). Os países do Anexo l se comprometeram a reduzir a emissão dos gases do efeito estufa entre 2008 e 2012. O Protocolo só entrou em vigor em 2005, com a ratificação da Rússia, pois necessitava ser ratificado (contar com a aprovação plena, inclusive dos respectivos Parlamentos Nacionais) por pelo menos $55 \%$ dos países signatários e, também, por países que representam, pelo menos, $55 \%$ das emissões globais do ano-base de 1990 (FIGUEIRA, 2005).

Como forma de atenuar a emissão de gases do efeito estufa, Estados Unidos, Europa e Brasil incrementaram os seus já existentes programas de 
biocombustíveis para gerar uma redução da utilização do petróleo com a finalidade de geração de energia para ser utilizada no transporte. Neste período, trabalhos de pesquisa como de Macedo (1997), constataram o potencial dos biocombustíveis em reduzir a emissão de gases do efeito estufa.

Figueira (2014), salienta para o fato de o crescimento da produção de biocombustíveis ter gerado uma série de debates no meio acadêmico e de políticas públicas relacionados aos aspectos positivos e negativos dos biocombustíveis. Quanto aos aspectos positivos ressalta-se a redução da emissão de gases do efeito estufa e a geração de renda. No entanto, existe a preocupação quanto ao impacto da produção de biocombustíveis sobre o desflorestamento e a maior utilização de herbicidas e fertilizantes provocando contaminação na água e no solo.

\section{OBJETIVOS}

O objetivo do artigo é o de realizar pesquisa bibliográfica e documental sobre os principais programas de biocombustíveis no mundo: americano, europeu e brasileiro.

Para se cumprir o objetivo geral, os seguintes objetivos específicos serão abordados:

- Descrição dos principais aspectos das políticas públicas para se incentivar o consumo e a produção de biocombustíveis nos Estados Unidos, Brasil e União Europeia

- $\quad$ Avaliação da variação efetiva da demanda e oferta de biocombustíveis nos Estados Unidos, Brasil e União Europeia.

\section{MATERIAIS E MÉTODOS}

A realização da pesquisa foi através de pesquisa bibliográfica e documental. A pesquisa bibliográfica é desenvolvida com base em material já elaborado, constituído principalmente de livros e artigos científicos. A pesquisa documental é realizada com documentos não analisados (GIL, 2007). Utilizou-se para a pesquisa documental de documentos oficiais do governo brasileiro, americano e europeu 
sobre os programas de biocombustíveis e de dados relacionados a demanda e oferta nestes países. Utilizou-se também de trabalhos científicos e jornalísticos para se avaliar os programas de biocombustíveis analisados.

\section{RESULTADOS}

Nos Resultados, apresenta-se as principais características do programa de etanol americano, brasileiro e europeu e o efetivo avanço na utilização de biocombustíveis nestes programas de biocombustíveis.

\subsection{Programa de biocombustível americano}

Estimulado pelo programa brasileiro, o programa americano (US and Gasohol) iniciou no começo da década de 1980 utilizando-se principalmente do milho como insumo. O principal objetivo era estabilizar o preço do milho e gerar uma alternativa para a gasolina importada. Na década de 1990, quando foi instituído o "Clean Air Act" nos EUA, estabelecendo-se um conjunto de padrões da qualidade do ar das áreas americanas (usualmente referidas às cidades de maior tamanho). Para reduzir o nível de poluição foram instituídos os programas de gasolina oxigenada de inverno e o de gasolina reformulada, ambos exigindo a adição de oxigênio na gasolina com o objetivo de reduzir a emissão de poluentes. Para efetuar a adição de oxigênio na gasolina necessita-se da utilização de MTBE ou etanol. Muitos estados americanos proibiram a utilização do MTBE devido a poluição da água incentivando a utilização de etanol (FIGUEIRA, 2005).

No início da década de 2000, iniciaram-se as metas federais para incentivar o uso de combustíveis alternativos. Aprovou-se em 2005 o "Energy Policy Act of 2005" incluindo o estímulo ao programa de combustíveis renováveis nos EUA. Em Dezembro de 2007 foi promulgado no parlamento americano uma emenda legislativa sobre o "Renewable Fuel Standard" estipulando uma meta crescente de demanda de biocombustíveis até atingir de 36 bilhões de galões americanos, aproximadamente 136 bilhões de litros, produzidos a partir de 
biocombustíveis convencionais e avançados, para serem demandados no ano de 2022, ver figura 1, (RENEWABLE FUEL ASSOCIATION, 2014).

Figura 1: Meta de demanda de biocombustíveis nos EUA pelo Renewable Fuel Standard, de 2008 até 2022. Unidade de medida: bilhões de litros.

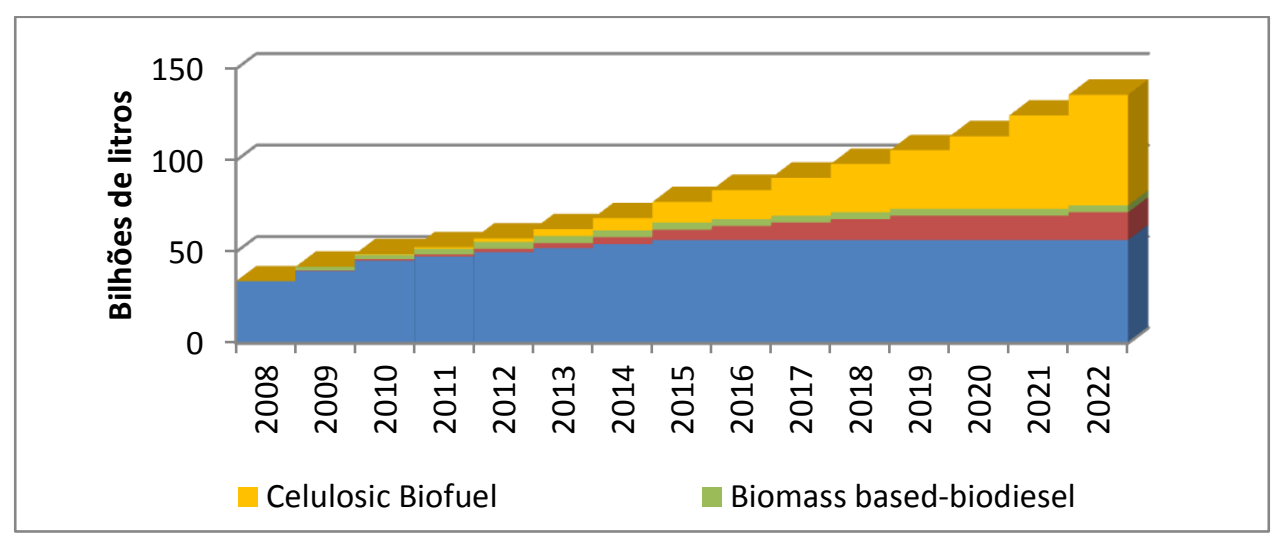

Fonte: RENEWABLE FUEL ASSOCIATION , 2014

Os Biocombustíveis convencionais (Renewable fuel) correspondem ao etanol produzido com grãos de milho, forma predominante de produção de biocombustíveis nos EUA. No programa americano, apenas são aceitos biocombustíveis que comprovadamente reduzam em pelo menos $20 \%$ a emissão de gases geradores do efeito estufa em relação à gasolina. Os biocombustíveis provenientes de celulose (Cellulosic Biofuel) são os procedentes de qualquer tipo de celulose, hemicelulose ou lignina e deve atender a $60 \%$ de redução da emissão de gases do efeito estufa em relação a gasolina. Os outros tipos de combustíveis avançados (Undifferentiated Advaced Biofuel) correspondem a qualquer tipo de biocombustível que reduza em pelo menos $50 \%$ a emissão de gases do efeito estufa em relação a gasolina. $O$ biodiesel proveniente de biomassa também deve reduzir em pelo menos $50 \%$ a emissão de gases do efeito estufa (RENEWABEL FUEL ASSOCIATION, 2014).

No entanto, o governo americano estuda alterar está meta. Estima-se que em 2015 será divulgado se a Agência de Proteção Ambiental Americana (Environmental Protection Agency -EPA) irá manter ou alterar a meta préestabelecia. A agência possui o poder de decisão de alterar parcial ou integralmente a meta de biocombustíveis caso a oferta doméstica não seja capaz de suprir a 
demanda ou o cumprimento da meta cause impacto na economia ou meio ambiente do estado, região ou nação (MCMINIMY, 2014).

Existe pressão de lobbies políticos contrários e favoráveis ao uso de biocombustíveis tanto sobre a Agência de Proteção Ambiental Americana como aos políticos americanos. O Instituto Americano do Petróleo defendem sempre a diminuição dos mandatos de etanol para aumentar a quantidade de petróleo bruto usada na cadeia de fornecimento. Alguns grupos ambientalistas também combatem o etanol devido a expansão do desflorestamento. Por outro lado, a Associação Nacional dos Produtores de Milho e outros grupos pró-etanol querem que os mandatos sejam ampliados (DEVANEY, 2014) .

Nastari (2014) salienta também que persiste a dúvida se os Estados Unidos irão cumprir a meta de demanda prevista no Renewable Fuel Standard ou irão efetivar uma demanda menor. Está em análise pelo governo americano uma redução da meta de combustíveis avançados dos 18,15 bilhões de galões $(68,71$ bilhões de litros) inicialmente planejados para 2014, para uma faixa entre 15,00 e 15,54 bilhões de galões, o que representaria uma redução significativa em relação à meta originalmente estabelecida de 2,63 a 3,15 bilhões de galões. A proposta, que ainda está sob revisão, respondeu às pressões da indústria de petróleo. O aumento do percentual de mistura na gasolina também tem sofrido questionamentos por parte da indústria automobilística, o que tem gerado mais um entraves para o crescimento do consumo de etanol no mercado norte-americano.

\section{Oferta de etanol nos Estados Unidos}

Para atender ao crescimento da demanda por etanol está em curso um amplo programa de investimentos para ampliar a capacidade de produção deste combustível, ver figura 2. Entre os anos de 2003 e 2009, a produção americana de etanol passou de 10 bilhões para 50 bilhões de litros de etanol, superando a produção brasileira e tornando-se o maior país produtor de etanol do mundo. 
Figura 2: Histórico da produção de etanol nos EUA, de 1990 até 2013.

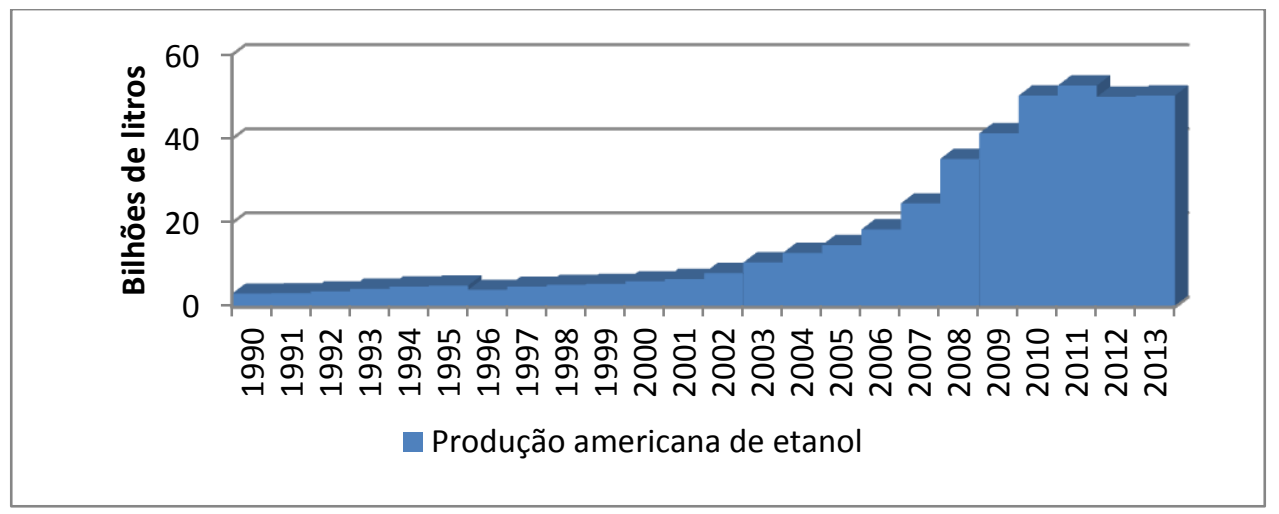

Fontes: Renewable Fuels Association, 2014.

O crescimento na produção de etanol americano se deve à forte intervenção governamental. Conforme a ALCO (1997 apud MORAES, 1999), embora não existam subsídios diretos para os produtores de milho produzirem etanol, o suporte do programa é feito através de um sistema de isenção fiscal no uso do produto como aditivo à gasolina. $\mathrm{O}$ nível dos subsídios que no início do programa era de 60 centavos de dólar por galão (aproximadamente U\$ 0,15 por litro de etanol), passando para 54 centavos por galão (aproximadamente US\$ 0,14 dólar por litro) em 1997.

Desde 2007, o etanol produzido com milho nos Estados Unidos conta com um subsídio de US\$ 0,12 por litro. Além disto, existe uma tributação incidente sobre o etanol importando de US\$ 0,14 por litro adicionado a uma tarifa ad valorem de 2,5\% (CRAGO ET AL., 2010) .

Além de produzir etanol internamente, o programa de etanol americano permite uma cota de importação de $7 \%$ sem pagar tarifa de importação para os países da América Central e Caribe integrantes do Caribbean Basin Initiative (CBI) (FIGUEIRA, 2005) .

\subsection{Programa de biocombustível brasileiro}

O programa de biocombustível brasileiro é principalmente com base no etanol, apenas em 2008 se inicia um programa de biodiesel implantando mistura de 
biodiesel no óleo diesel. O programa de etanol brasileiro iniciou-se na década de 1970 com o Programa Nacional do álcool como alternativa para reduzir a utilização de petróleo ${ }^{2}$. Desenvolveu-se deste então a produção e utilização do etanol anidro misturado na gasolina e o etanol hidratado com a possibilidade de ser consumido sem a necessidade de mistura, mas necessitava-se um automóvel com motor exclusivo para o uso de etanol.

Em meados da década de 1980 e 1990, o programa brasileiro entrou em estagnação e crise devido a redução do preço internacional do petróleo, a ampliação da produção brasileira, a ampliação das exportações de açúcar pelas usinas brasileiras e a crise fiscal do estado brasileiro impondo redução dos subsídios para a produção e demanda de etanol no mercado interno.

$\mathrm{Na}$ década de 2000, ocorre uma retomada da produção e consumo do etanol brasileiro devido a ampliação da venda de veículos bicombustíveis e a possibilidade de crescimento da demanda por etanol no mercado brasileiro e a possibilidade de exportação de petróleo principalmente para os programas de biocombustíveis americano e europeu.

O governo federal lançou em 2006 e 2007, o Plano Nacional de Agroenergia (BRASIL, 2006) e o Plano Nacional de Mudanças Climáticas (BRASIL, 2007) almejando ampliar a participação do etanol brasileiro tanto no mercado interno e estimulando outros países a ampliarem a demanda por biocombustíveis em geral e etanol em particular e auxiliando outros países a ampliar a produção de etanol. O governo brasileiro pretende com os planos estimular também a cooperação técnica com outros países para o plantio de cana-de-açúcar visando contribuir para a desconcentração da oferta de etanol no mercado internacional, o que tornaria mais estável e equilibrada a oferta deste produto no mercado internacional, permitindo, assim, a expansão sustentável da demanda. Com estas medidas, o Brasil estaria contribuindo para a mitigação das emissões de gases do efeito estufa para além das fronteiras e propiciando uma grande oportunidade aos países de economia predominantemente agrícola de aumentar suas receitas de exportação.

${ }^{2}$ Na década de 1970, ocorreu o primeiro e o segundo choque de petróleo elevando o preço internacional do barril de petróleo. A elevação do preço do petróleo ampliou o valor das importações brasileiras no período gerando problemas no Balanço de Pagamentos. 
Iniciou-se ainda um plano nacional para a mistura de biodiesel no óleo diesel brasileiro. Inicialmente, a mistura compulsória foi de 2\% a partir de 1 de janeiro e $2008 \mathrm{com}$ a persepectiva de ampliar o nível de mistura nos anos seguintes (BRASIL, 2007). No ano de 2014, o governo anunciou ampliação da mistura para 7\% (Portal Brasil, 2015). Conforme dados fornecidos por Brasil (2015), produção de biodiesel no Brasil passou de 736 milhões de litros em 2005 para 3,4 bilhões em 2014.

A partir da safra 2003/04 passou a ocorrer investimento das usinas brasileiras para a ampliar a produção de etanol, ver figura 3 , destinados para 0 mercado interno e com as expectativas de exportação. O governo brasileiro concedeu financiamento para os investimentos no setor, Borges; Costa (2013) destacam a importância do financiamento público exercido pelo Banco Nacional de Desenvolvimento Econômico e Social (BNDES) com desembolso entre 2001 e 2008 de aproximadamente 23,7 bilhões de reais em valores reais de 2012 (os valores nominais do desembolso foram corrigidos pelo IGP-DI para 2012) destinados para a expansão, financiamento para compra de máquinas e equipamentos e implantação de novas unidades.

Figura 3: Produção de etanol anidro e hidratado no Brasil entre as safras de 1990/91 e 2013/14.

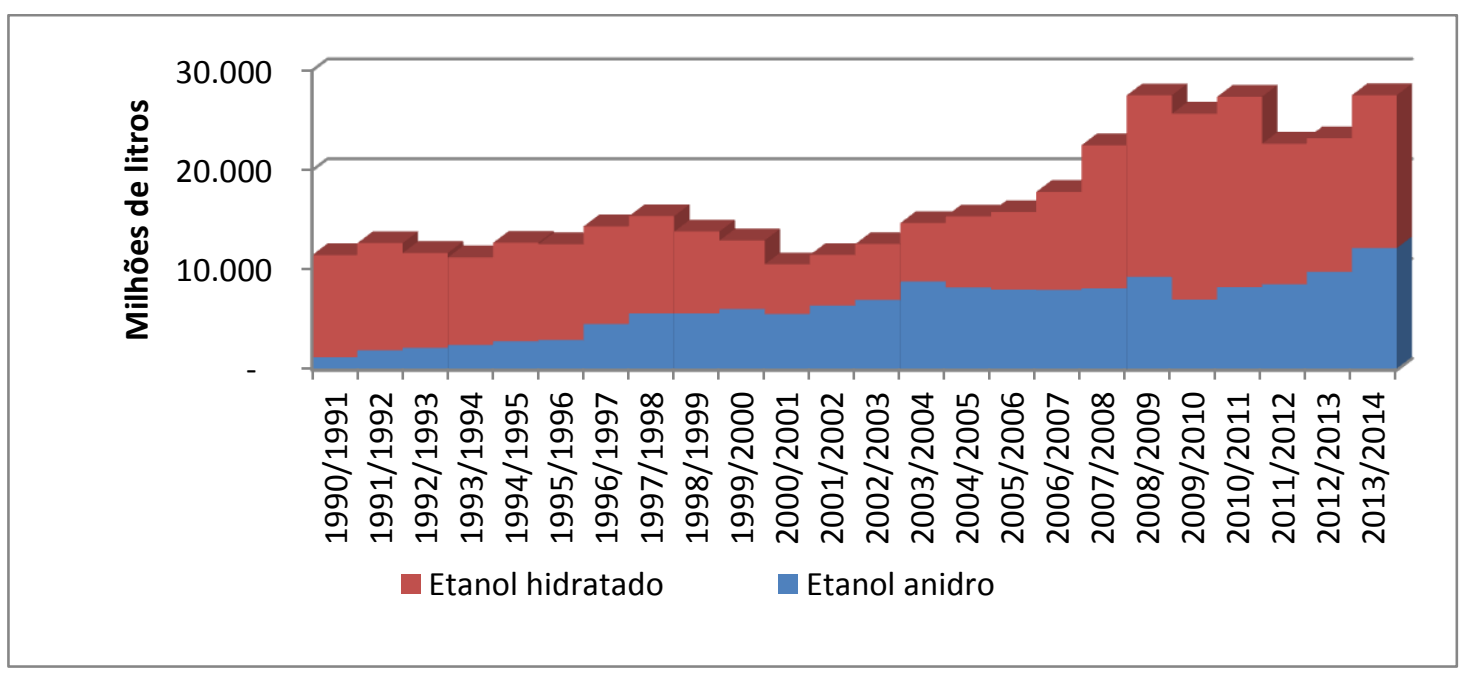

Fonte: UNIÃO DA INDÚSTRIA CANAVIEIRA - UNICA, 2015 


\subsection{Programa de biocombustível na União Europeia}

Tendo como intuito estimular os países europeus a adotarem programas de biocombustíveis, o Parlamento Europeu adotou a estratégia de elaborar uma directiva destinada aos países membros. Em 8 de maio de 2003, foi publicada uma diretiva do Parlamento Europeu e do Conselho da União Europeia relativa à promoção da utilização de biocombustíveis ou de outros combustíveis renováveis nos transportes rodoviários. Esta diretiva, favorável à utilização de biocombustíveis, considerou os seguintes aspectos: - a promoção da produção e do uso de biocombustíveis poderá contribuir para redução da dependência das importações de energia e para diminuir as emissões de gases causadores do efeito estufa (FIGUEIRA, 2011).

A DIRECTIVA DO PARLAMENTO EUROPEU E DO CONSELHO estabeleceu as seguintes metas de biocombustíveis: Os Estados-Membros deverão assegurar que seja colocada nos seus mercados uma proporção mínima de biocombustíveis e de outros combustíveis renováveis, e estabelecem metas indicativas nacionais para o efeito. $O$ valor de referência dessas metas, calculado com base no teor energético, é de $2 \%$ de toda a gasolina e de todo o gasóleo utilizados para efeitos de transporte colocados no mercado, até 31 de Dezembro de 2005. O valor de referência dessas metas, calculado com base no teor energético, é de 5,75\% de toda a gasolina e de todo o gasóleo utilizados para efeitos de transporte colocados no mercado, até 31 de dezembro de 2010 (UNIÃO EUROPEIA, 2003).

Como se constatou um não cumprimento da meta de energia renovável em 2005, o objetivo de $2 \%$ não foi alcançado e um estudo da Comissão apontou que os objetivos estabelecidos pelos Estados-Membros tinham o potencial de chegar somente a uma quota de $1,4 \%$ de mistura de biocombustíveis nos combustíveis fósseis (Ladu, 2009 apud FIGUEIRA, 2010). Além disto, existe uma grande polêmica relativa ao impacto dos biocombustíveis nos preços dos alimentos e no incremento da devastação de biomas para a produção de biomassa, principalmente nos países em desenvolvimento (FIGUEIRA 2010).

Efetuando-se uma análise crítica da primeira diretiva e procurando estimular os países membros a intensificarem os programas de biocombustíveis, em 2009, o 
Parlamento Europeu redigiu alterações na Diretiva de 2003. A principal alteração relaciona-se a tornar-se compulsória a utilização de combustíveis renováveis no setor de transporte para cada Estado-Membro no ano de 2020. A quota de energia renovável para o setor de transporte deverá ser de $10 \%$ do total da energia utilizada para transporte. Abriu-se ainda a possibilidade de importação de biocombustíveis de outros países. No entanto, ainda não está definido quais serão os critérios de sustentabilidade exigidos pelo Parlamento Europeu e quais serão os países beneficiados pela abertura de mercado. Lembrando da existência de acordos preferenciais de importação do mercado europeu de países africanos e do pacífico, principalmente para antigas colônias de países europeus na África e na América Central e no Caribe ( FIGUEIRA, 2010).

Os países da União Europeia estão em processo de discussão sobre os critérios de sustentabilidade dos biocombustíveis produzidos domesticamente e/ou importados. Pois a discussão sobre sustentabilidade e redução de emissão de gases geradores do efeito estufa foi um dos grandes fatores motivadores para a implantação dos programas de biocombustíveis. Neste sentido, existe uma preocupação em torno do impacto da expansão da produção de biomassa para a produção de biocombustíveis sobre os biomas- principalmente em países do terceiro mundo, com legislações mais permissivas com relação ao desflorestamento de suas áreas - e sobre a perda de terras de populações locais. A concorrência com a produção de alimentos também é um tema a ser considerado. Fazendo-se necessário assegurar que a produção de biocombustíveis não esteja concorrendo com a produção de alimentos. A utilização do milho, do trigo e da beterraba para a produção de biomassa pode desencadear em elevação dos preços destes produtos para a alimentação. Questões sociais, como o trabalho escravo, também são critérios importantes a serem considerados nos critérios de sustentabilidade (FIGUEIRA, 2010).

Constata-se crescimento do uso de biocombustíveis na União Europeia entre 2006 e 2011. Atingindo mais de 20 bilhões de litros de biodiesel e bioetanol consumidos conjuntamente. Após este período inicia-se decrescimento na demanda apesar da diretiva do parlamento europeu, ver figura 4. Constata-se ainda uma maior utilização do biodiesel em relação ao etanol. 
Figura 4 : Evolução da demanda europeia por biodiesel e etanol e da produção Europeia de biodiesel e etanol, de 2006 até 2015.

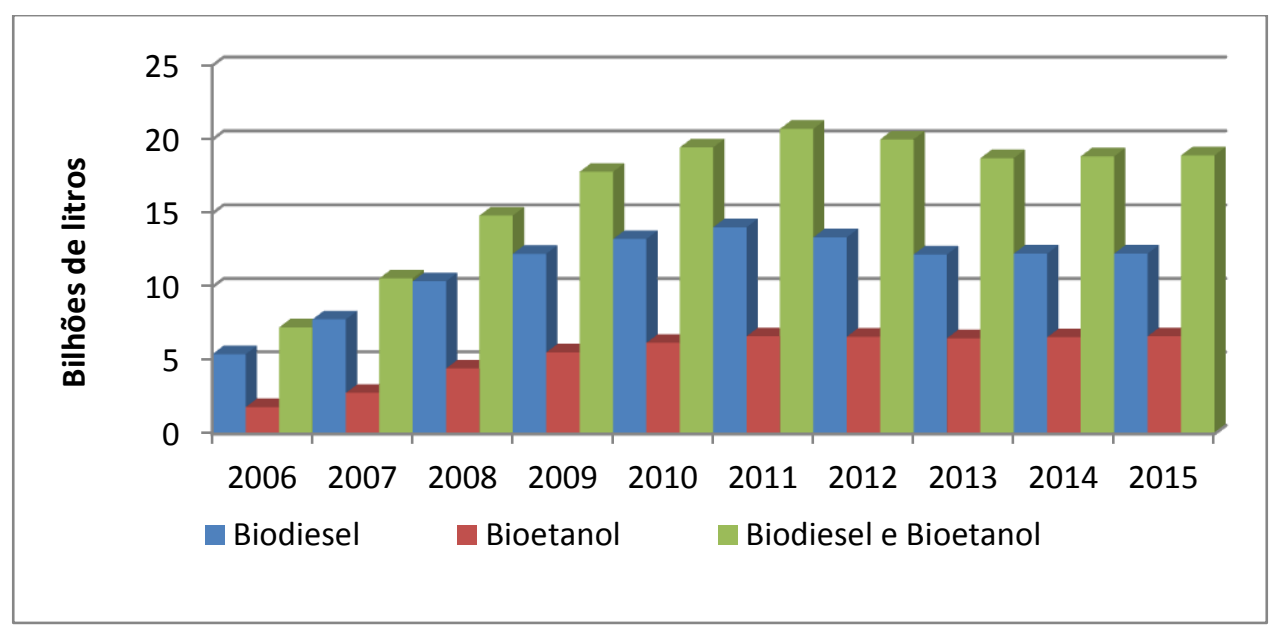

Fonte: FLACH et. Al , 2009 e FLACH; BENBDZ; LIEBERZ, $2014^{3}$.

Apesar do crescimento da utilização de biocombustíveis na União Europeia, a mistura de biocombustíveis nos combustíveis fósseis se encontra atualmente em aproximadamente $7 \%$ e não nos $10 \%$ almejados. Ao invés de ampliar a utilização de biocombustíveis para atingir os 10\%, a União Europeia estuda reduzir a meta de utilização de biocombustíveis para 7\%. Se isto ocorrer, a configuração do programa de biocombustíveis europeu deverá ficar no atual nível (FLACH; BENDZ; LIEBERZ, 2014)

Um dos motivos para a maior utilização do biodiesel em relação ao bioetanol na União Europeia se refere ao declínio na utilização de gasolina e elevação na utilização de óleo diesel como combustível automotivo, como constatase na figura 5. Conforme Linn (2014), vem ocorrendo elevação nas vendas de automóveis de passeio movidos a óleo diesel na União Europeia desde a década de 1980. O crescimento destes veículos variam muito nos países europeus, atingindo a marca de $75 \%$ na França e Bélgica, $25 \%$ na Holanda e 0\% no Reino Unido. Explicase o crescimento da venda deste tipo de veículos pela redução dos gastos do consumidor com a utilização deste tipo de combustível, pois o carro movido a óleo diesel é mais eficiente em comparação com o movido a gasolina permitindo rodar

3 Os valores de 2006 até 2012 são observados, o valor de 2013 é estimado e o de 2014 e 2015 são projeções. 
mais quilómetros por litro. Além disto, a tributação incidente sobre o óleo diesel é menor se comparada a gasolina em muitos países europeus.

Figura 5: Evolução da demanda Europeia por gasolina e óleo diesel entre 2006 e 2015.

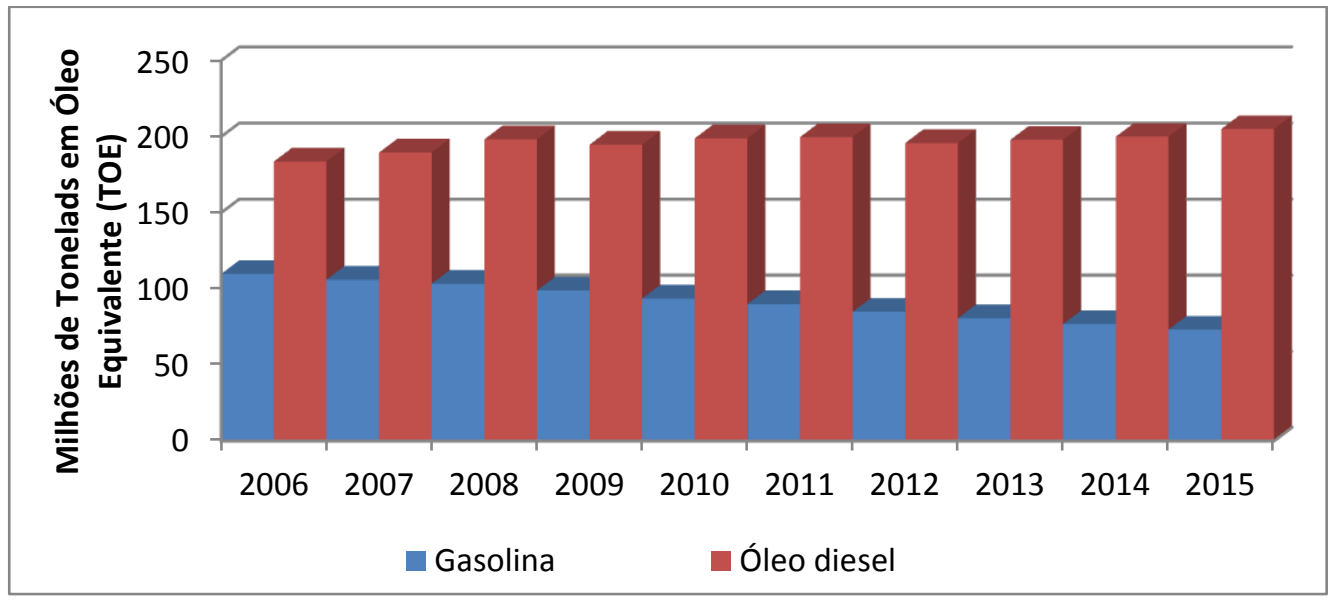

Fonte: FLACH et. Al (2009) e FLACH; BENBDZ; LIEBERZ (2014) .

O etanol europeu é majoritariamente produzido com beterraba. No entanto, vem ocorrendo redução da participação da beterraba na produção de etanol europeia, passando de uma participação de 70\% em 2008 para uma estimativa de participação de $51 \%$ em 2015. O milho é a segunda matéria-prima com maior participação na produção de etanol americana, passando de uma participação de $9 \%$ em 2008 para uma estimativa de participação de $28 \%$ em 2015. O trigo também ampliou a participação de 12\% em 2008 para uma estimativa de participação de 17\% em 2015 (FLACH; BENBDZ; LIEBERZ, 2014).

Para expandir a produção doméstica, a União Europeia concede subsídios para o produtor doméstico e tributa as importações. Conforme BTG (2004 apud EUROPEAN BIOMASS INDUSTRY ASSOCIATION, 2012) existem subsídios concedidos para a produção na União Europeia de aproximadamente 0,59 Euros o litro para o etanol produzido com trigo e 0,6 Euros por litro o etanol produzido com beterraba. Infelizmente, BTG (2004) não mensurou os custos do etanol produzido

\footnotetext{
${ }^{4}$ Os valores de 2006 até 2012 são observados, o valor de 2013 é estimado e o de 2014 e 2015 são projeções
} 
com milho. Além disto, existe uma tarifa de importação Conforme Pires; Schechtman (2010), O etanol brasileiro sofre barreiras tributárias para entrar na União Europeia . O bloco impõe duas alíquotas de importação do etanol: uma de 0,192 euros o litro para o etanol não desnaturado e outra de 0,102 euros para o etanol desnaturado. 0 Brasil exporta para a União Europeia principalmente álcool não desnaturado

Portanto, grande parte do etanol utilizado nos programas de biocombustíveis da União Europeia são produzidos localmente. Existindo ainda acordos comerciais como o Ageement with African, Caribbean and Pacific com países da África e Caribe isentando o biocombustível produzido nestes países de tributação.

\section{DISCUSSÕES}

Constatou-se nos principais programas de biocombustíveis do mundo um processo de implantação dos programas em meados da década de 2000, coincidindo com a ratificação do protocolo de Quioto, uma ampliação da demanda e da oferta de biocombustíveis nestes programas até o final da década de 2000 e uma estaganação da demanda e da oferta de biocombustíveis no início da década de 2010.

As críticas aos programas de biocombustíveis relacionadas a ampliação dos preços dos alimentos, a mudança do uso da terra, as crises econômicas reduzindo o nível de crescimento econômico e da renda e a crise fiscal nos estados nacionais, reduzindo a possibilidade de gastos públicos e a pressão da indústria petrolífera inibiram o crescimento da utilização dos biocombustíveis no início da década de 2010.

\section{CONCLUSÃO}

Na década de 2000, Estados Unidos, Brasil e União Europeia revigoraram os seus programas de biocombustíveis com a finalidade de reduzir a emissão de gases do efeito estufa, geração de renda para a agricultura e reduzir a dependência da importação de petróleo. 
O objetivo da pesquisa foi o de realizar uma pesquisa bibliográfica e documental para se descrever as características dos programas de biocombustíveis destes países e a evolução da demanda e oferta de biocombustíveis destes programas . No caso brasileiro, foca-se no programa de etanol, maior programa de biocombustível brasileiro.

Constatou-se em meados da década de 2000, a elaboração dos programas públicos para se intensificar a utilização de biocombustíveis visando reduzir a emissão de gases do efeito estufa nos Estados Unidos, União Europeia e Brasil. Os programas efetivamente ampliaram a demanda e a oferta nacional de biocombustíveis até o final da década de 2000.

A ampliação da oferta de biocombustíveis desencadeou uma série de debates nos países sobre os seus reais benefícios, argumentando sobre os seus impactos na mudança do uso da terra, na elevação do preço dos alimentos e no uso de herbicidas e fertilizantes impactando na água.

No início da década de 2010, constata-se que os programas de biocombustíveis americano, europeu e brasileiro entram em um processo de estagnação motivados pelos argumentos dos impactos ambientais gerados pelos biocombustíveis, pela redução do crescimento econômico e consequentemente da demanda por combustíveis e da possibilidade de gastos públicos e pela pressão da indústria petrolífera.

\section{REFERÊNCIAS}

BRASIL. AGÊNCINA NACIONAL DO PETRÓLEO GÁS E BIOCOMBUSTíVEIS. Produção de Biodiesel. Disponível em: http://www.anp.gov.br. Acesso em 25 mar. 2015.

BRASIL. GOVERNO FEDERAL -. Plano Nacional Sobre Mudança do Clima. Brasília. Comitê Interministerial sobre Mudança do Clima. 2007.

BRASIL. MINISTÉRIO DA AGRICULTURA, PECUÁRIA E ABASTECIMENTO. Plano Nacional de Agroenergia 2006-2011. Brasília: EMBRAPA Informação Tecnológica 2006.

BRASIL. BANCO NACIONAL DE DESENVOLVIMENTO ECONÔMICO E SOCIAL; MINISTÉRIO DE CIÊNCIA E TECNOLOGIA. Efeito estufa e a convenção sobre mudança no clima. BRASÍLIA: REPÚBLICA FEDERATIVA DO BRASIL,1999.

BORGES, Ana Claudia Giannini.; COSTA, Vera Mariza Henriques de Miranda. O processo de concentração e de centralização do capital e o financiamento da produção sucroalcooleira no Brasil. VII Simpósio Nacional de Geografia Agrária. João Pessoa, Paraíba. 2013. 
CRAGO, Cristine Lasco et al. Competitiviness of Brazilian Sugarcane Ethanol compared to US Corn Ethanol. Poster prepared for presentation at the Agricultural \& Applied Economics Association 2010. pp.1-38. AAEA,CAES, \& WAEA Joint Annual Meeting, USA, Denver, Colorado, July 25-27, 2010 Disponível em:http://ageconsearch.umn.edu/bitstream/60895/2/Crago CostofCornandSugarcaneEthanol AAEA. pdf. Acesso em: 02 fev 2015.

DEVANEY, Tim. Depois de indicar uma redução do mandato de etanol no final do ano passado, agora a administradora da EPA, Gina McCarthy, sinaliza uma mudança de $\mathbf{1 8 0}$ graus e pode aumentar os limites de etanol. Tradução de Siqueira, Leonardo. Nova cana. 16 set. 2014.

EUROPEAN BIOMASS INDUSTRY ASSOCIATION . Bioethanol in the world. disponível em: Bruxelas. Bélgica. 2012. Disponível em: http://www.eubia.org. Acesso em 02 nov. 2014.

FIGUEIRA, Sérgio Rangel Fernandes Características nacionais e estaduais do crescimento da demanda por etanol hidratado, gasolina $\mathrm{C}$ e ambos os combustíveis no período de 2005 até 2013 no Brasil. Periódico Eletrônico do Fórum Ambiental da Alta Paulista, Tupã - SP. 2014. pp.0119.

FIGUEIRA, Sérgio Rangel Fernandes. Impactos das diretivas do parlamento europeu e do conselho nos programas de biocombustíveis na União Europeia - Uma análise da demanda, oferta e normas socioambientais. In: IX Encontro da Sociedade Brasileira de Economia Ecológica, 2011, Brasília. Anais do IX Encontro da Sociedade Brasileira de Economia Ecológica, 2011. PP 1-21.

FIGUEIRA, Sérgio Rangel Fernandes. Programas de biocombustíveis da União Européia. In: SOBER, 2010. 2010, Campo Grande. Anais do $48^{\circ}$ Congresso SOBER, 2010. PP 1-21.

FIGUEIRA, Sérgio Rangel. Os programas de álcool como combustível nos EUA, no Japão e na União Européia e as possibilidades de exportação do Brasil. 2005. Tese (Doutorado em Ciências, Área de Concentração: Economia Aplicada) - Escola Superior de Agricultura "Luiz de Queiroiz", Universidade de São Paulo, Piracicaba, 2005. 182 p.

FLACH, Bob; BENDZ, Karin; LIEBERZ, Sabine - EU - 28 Biofuels Annual 2014. USA. USDA

Foreign Agricultural Service. Global Agricultural Information Network.. Disponível em:

http://gain.fas.usda.gov/Recent\%20GAIN\%20Publications/Biofuels\%20Annual The\%20Hague EU-

28 7-3-2014.pdf. Acesso em 20 out. 2014. 40p.

FLACH, Bob et. al. EU-27 BIOFUELS ANNUAL - Annual Report 2009. USA. USDA Foreign Agricultural Service. Global Agricultural Information Network.. Disponível em: <http://gain.fas.usda.gov/.> Acesso em: 20 fev.2014. 40p.

GIL, Antônio Carlos Métodos e Técnicas de Pesquisa Social.. $5^{\circ}$ Ed. São Paulo. Editora Atlas S.A. 2007. $206 p$

MACEDO, Isaias de Carvalho. Greenhouse gas emissions and bio-ethanol production/utilization in Brazil. Piracicaba: Centro de Tecnologia Copersucar, jan.1997.13 p.

MCMINIMY, Mark. EPA Delays Decision on 2014 Renewable Fuel Standard to 2015. USA. Federation of American Scientistis. Disponível em: https://www.fas.org/sgp/crs/misc/lN10189.pdf. Acesso em: 20 jan. 2015.

MORAES, Marcia Azanha Ferraz Dias de. A Desregulamentação do Setor Sucroalcooleiro Brasileiro. 1999. Tese (Doutorado em Ciências. Área de Concentração: Economia Aplicada) Escola Superior de Agricultura "Luiz de Queiroz", Universidade de São Paulo, Piracicaba, 1999. 284 p. 
NASTARI, Plinio. Possibilidade de redução de metas de RFS gera instabilidade no mercado de biocombustíveis. Canal Jornal da Bioenergia. Disponível em: http://www.canalbioenergia.com.br/possibilidade-de-reducao-de-metas-de-rfs-gera-instabilidade-nomercado-de-biocombustiveis/ Acesso em : 11 out. 2014

PEREIRA, André ; MAY, Peter Herman. Economia do aquecimento global. In: MAY, Peter Herman; LUSTOSA, Maria Cecília Junqueira.; VINHA, Valéria da. ECONOMIA DO MEIO AMBIENTE. RIO DE JANEIRO: ELSEVIER 2003.

PIRES, A.; SCHECHTMAN, R. Políticas internacionais de biocombustíveis. Sousa, Eduardo Leão de Souza.; Macedo, Isaias de Carvalho Etanol e Bioeletricidades. A cana-de-açúcar no futuro da matriz energética. São Paulo. Editora Luc Projetos de Comunicação LTDA. 2010. pp192-224

PORTALBRASIL. Governo aumenta percentual de biodiesel no óleo diesel. Governo Brasileiro. Disponível em: http://www.brasil.gov.br. Acesso em 20 mai. 2015.

RENEWABLE FUELS ASSOCIATION. Annual Ethanol Industry Outlook 2014. USA . Disponível em: <http://www.ethanolrfa.org/pages/renewable-fuel-standard/> Acesso em 05 jan. 2015. 40p.

UNIÃO DA INDÚSTRIA DE CANA- DE- AÇÚCAR -UNICA . Produção brasileira de álcool anidro e hidratado. UNICADATA.Disponível em: http://www.unicadata.com.br. Acesso em 02 fev.2015.

UNIÃO EUROPEIA. Directiva do parlamento europeu e do conselho. Jornal Oficial $n^{\circ}$ L123 de 17/05/2003, p.0042-0046. Disponível em: <http://www.ebb-eu.org/legis/OJ\%20promotion\%20POR.pd 